\title{
Effect of Synthetic Emulsifier and Natural Biosurfactant on Feed Process and Quality of Pelletized Feed in Broiler Diet
}

\section{-Author(s)}

\section{Cheah YS',II}

Loh TC,"II

Akit $\mathrm{H}^{\prime}$

Kimkool S"II

Department of Animal Science, Faculty of Agriculture, Universiti Putra Malaysia, 43400 UPM Serdang, Malaysia

" Institute of Tropical Agriculture, Universiti Putra Malaysia, 43400 Serdang, Selangor, Malaysia

II' Department of Feed Technology, Charoen Pokphand Holdings, 42000 Port Klang, Malaysia

\section{Mail Address}

Corresponding author e-mail address

T.C. Loh

Department of Animal Science, Faculty of Agriculture, Universiti Putra Malaysia, 43400 UPM Serdang, Malaysia

Tel: $\quad$ 603-8947-4814

Email: tcloh@upm.edu.my

\section{neywords}

Emulsifier, Feed intact form, Pellet durability index, Pellet quality, Starch gelatinization.

\section{ABSTRACT}

A feed production trial was conducted to study the effect of synthetic emulsifier and natural biosurfactant the process and quality of pelletized broiler feed. A corn-soy based broiler diet was formulated with fixed ratio 2:1 of oil-to-water with two types of emulsifiers, namely glyceryl polyethylene glycol ricinoleate synthetic emulsifier and lysophosphatidylcholine natural biosurfactant. T1: Basal diet with no water and no emulsifier; T2: Basal diet with water and no emulsifier; T3: Basal diet with water and synthetic emulsifier glyceryl polyethylene glycol ricinoleate; T4: Basal diet with water and a natural biosurfactant lysophosphatidylcholine as comparative treatment. The treatment diets were manufactured by a commercial feed mill. The electricity cost and meal temperature were measured during the process of milling. Composite samples were collected from different processed points, tested for physical properties, chemical stability and biostability of pelletized feed. Pellet quality of emulsifier supplemented diets was significantly $(p<0.05)$ improved in crumble and pellet intact form. Correlation between emulsifier and pelletize processed cost was not observed in this present study. No deteriorate effect was observed in hydrolytic rancidity (AV), oxidation rancidity (PV), mold count, moisture content and water activity. However, percentage of starch gelatinization on pelletized feed was significantly $(p<0.0001)$ improved in both types of emulsifier treated diets. These results demonstrated that the addition of emulsifier to broiler diet improved pellet quality to some extent although significant difference between synthetic emulsifier and natural biosurfactant was not observed.

Abbreviations: AV, acid value; PV, peroxide value; amp, ampere; vol, voltage; T/h, tonne per hour; kW, kilowatt; Aw, water activity; PDI, pellet durability index

\section{INTRODUCTION}

Alongside with the rise of ingredient price and energy cost, feed formulation highly affected the shrinking of profit margin. Inclusion of the cheapest energy source from high density oils and fats becomes a common practice by many nutritionists (Buchanan et al., 2010). However, inclusion of more than three percent of oil may have a negative impact in feed manufacturing (Attawong et al., 2014). It tends to produce low quality feed with soft pellet and low durability (Cavalcanti \& Behnke, 2005). Process of pelletizing broiler feed, requires inclusion of steam at conditioning process (CPM California Pellet Mill Co.). However, steam and oil are not compatible between phases during feed milling. Moritz et al. (2002) demonstrated that pellet quality do not exhibit any improved effect on formulation diet which contain high amount of fat. Overlooking of feed quality in terms of pellet hardness, 
becomes a common phenomenon in most regions of the country as to compromise the feed mill efficiency and cost margin in feed formulation (Buchanan et al., 2010). Concept of emulsifier supplementation was introduced into feed industry as latest technology to improve in feed quality (Ziggers, 2012). Emulsifier possesses properties which are capable of reducing the interfacial tension between two immiscible phases of oil and water (Hasenhuettl \& Hartel, 2008). Steam penetration of conditioner during feed process is expected to be achieved, leading to feed quality improvement. Application of emulsifier has been expected to improve the feed process' efficiency and feed quality. However, not many researches have been conducted on emulsifier technology in pelletized poultry feed. Thus, the objective of this study was to identify the effectiveness of synthetic emulsifier glyceryl polyethylene glycol ricinoleate compared with biosurfactant lysophosphatidylcholine in feed process and quality of pelletized broiler feed.

\section{MATERIAL AND METHODS}

\section{Diet treatment and design}

A corn-soy based diet was formulated by the least-cost Brill feed formulation software (Feed Management Systems, Inc.), meeting the nutritional recommendations of Cobb 500 (Cobb-vantress, 2015). The composition of ingredients and analyses of nutrient contents for starter and grower diets were presented in Tables 1 and 2, respectively. A 2-phase feeding program was adopted; starter crumble feed (1-14 days) and grower pellet feed (15-35 days). All diets were isocaloric, isonitrogenous and contained similar digestible amino acid percentages. Total oil inclusion, as formulated by least-cost formulation,

Table 1 - Ingredients of starter diet formulation

\begin{tabular}{|c|c|c|c|c|c|}
\hline \multirow{2}{*}{ Ingredient } & \multirow{2}{*}{ Units } & \multicolumn{4}{|c|}{ Starter Diet, 1-14 days } \\
\hline & & Treatment 1 & Treatment 2 & Treatment 3 & Treatment 4 \\
\hline Corn meal & $\%$ & 43.921 & 43.921 & 43.831 & 43.871 \\
\hline Soybean meal 46\% & $\%$ & 42.271 & 42.271 & 42.271 & 42.271 \\
\hline 1Crude palm oil @ mixer & $\%$ & 2.000 & 2.000 & 2.000 & 2.000 \\
\hline ²Crude palm oil @ post pelleting & $\%$ & 4.450 & 4.450 & 4.500 & 4.450 \\
\hline Rice bran & $\%$ & 2.190 & 2.190 & 2.190 & 2.190 \\
\hline Corn gluten meal $60 \%$ & $\%$ & 0.500 & 0.500 & 0.500 & 0.500 \\
\hline Di-calcium phosphate $18 \%$ & $\%$ & 1.784 & 1.784 & 1.784 & 1.784 \\
\hline Limestone & $\%$ & 1.109 & 1.109 & 1.109 & 1.109 \\
\hline Salt & $\%$ & 0.310 & 0.310 & 0.310 & 0.310 \\
\hline DL-methionine 99\% & $\%$ & 0.308 & 0.308 & 0.308 & 0.308 \\
\hline${ }^{3}$ Premix & $\%$ & 0.800 & 0.800 & 0.800 & 0.800 \\
\hline Sodium bicarbonate & $\%$ & 0.220 & 0.220 & 0.220 & 0.220 \\
\hline L-Lysine 78\% & $\%$ & 0.070 & 0.070 & 0.070 & 0.070 \\
\hline Choline chloride 75\% & $\%$ & 0.050 & 0.050 & 0.050 & 0.050 \\
\hline L-Threonine $98.5 \%$ & $\%$ & 0.018 & 0.018 & 0.018 & 0.018 \\
\hline${ }^{4}$ Synthetic emulsifier & $\%$ & - & - & 0.050 & - \\
\hline${ }^{5}$ Natural biosurfactant & $\%$ & - & - & - & 0.050 \\
\hline Water & $\%$ & - & 1.000 & 1.000 & 1.000 \\
\hline \multicolumn{6}{|l|}{ Analysed composition } \\
\hline${ }^{6} \mathrm{GE}$ & $\mathrm{kcal} / \mathrm{kg}$ & 4,155 & 4,162 & 4,159 & 4,168 \\
\hline Dry matter & $\%$ & 89.0 & 88.4 & 88.2 & 88.9 \\
\hline Crude protein & $\%$ & 24.2 & 24.4 & 24.5 & 24.3 \\
\hline Calcium & $\%$ & 0.98 & 0.97 & 0.99 & 0.98 \\
\hline Total phosphorus & $\%$ & 0.79 & 0.78 & 0.77 & 0.78 \\
\hline Lysine & $\%$ & 1.41 & 1.43 & 1.42 & 1.43 \\
\hline Methionine & $\%$ & 0.58 & 0.57 & 0.57 & 0.58 \\
\hline
\end{tabular}

${ }^{1}$ Crude palm oil added during mixing process

${ }^{2}$ Crude palm oil added after pelleting process

${ }^{3}$ Supplied per kg of diet: Fe 40 mg; Zn 100 mg; Mn120 mg; Cu 20 mg; Se 0.3 mg; vitamin A 12kIU; vitamin D $4.4 k I U ;$ vitamin E 57 mg; vitamin K 2.8 mg; vitamin B, 3.06 mg; vitamin B 6.72 mg; vitamin $B_{6} 5.49$ mg; vitamin $B_{12} 0.028$ mg; niacin 67.3 mg; folic acid 1.33 mg; pantothenic acid 14.8 mg; biotin 0.26 mg; ethoxyquin 100 mg; growth promoter 140 mg; anticoccidial $200 \mathrm{mg}$; mold inhibitor $500 \mathrm{mg}$.

${ }^{4}$ Each $1 \mathrm{~kg}$ contains $100 \%$ glyceryl polyethylene glycol ricinoleate(Bredol ${ }$, Akzo Nobel, Sweden)

${ }^{5}$ Each $1 \mathrm{~kg}$ contains $250 \mathrm{~g}$ lysophosphatidylcholine (Lysoforte ${ }^{\mathrm{TM}}$, Kemin Industries)

${ }^{6}$ Gross energy 
was added into feed milling through mixing process and post pelleting spray. Two percent of oil was added into the mixer while the remaining percentage of the oil was added during post pelleting spray. Treatment 1 consisted of basal diet with $2 \%$ of oil added into the mixer prior to pelleting; Treatment 2 consisted of basal diet with $2 \%$ of oil and $1 \%$ of water, added directly into the mixer through individual spray nozzle; Treatment 3 consisted of basal diet with $2 \%$ of oil, $1 \%$ of water and $0.05 \%$ of synthetic emulsifier, preblended through an emulsitron system with emulsion order sequence of oil-, emulsifier- and water at $60^{\circ} \mathrm{C}$ for 3 minutes before it was introduced into the mixer; Treatment 4 consisted of basal diet with $2 \%$ of oil, $1 \%$ of water and $0.05 \%$ of natural biosurfactant added directly into the mixer as comparative treatment. Similar treatments were applied for grower pellet feed.
The four experimental diets were manufactured in four replicates, in a completely randomized design.

\section{Manufacturing and facilities}

All diets were produced by a commercial feed mill, and pelleted at the same pellet mill. Corn and soybean meal were ground through Roskamp Champion Model 20x54 hammer mill, with screen aperture of 3x3mm. All ingredients were mixed in Heavy Duty Double Action Ribbon Horizontal Mixer, Hough International Model HFM 205 with 3.5 tonne capacity. All diets were homogenized mixed for 120 seconds dry mixing time, and then for another 180 seconds wet mixing time. Mash feed from mixer was conveyed into Munch Type 50-275 double feeder conditioners with steam inlet temperature of $120^{\circ} \mathrm{C}$ and pressure of 2 bars for 45 seconds of retention time. All diets were formed into

Table 2 - Ingredients of grower diet formulation

\begin{tabular}{|c|c|c|c|c|c|}
\hline \multirow{2}{*}{ Ingredient } & \multirow{2}{*}{ Units } & \multirow{2}{*}{ Treatment 1} & \multirow[b]{2}{*}{ Treatment 2} & \multirow[b]{2}{*}{ Treatment 3} & \multirow[b]{2}{*}{ Treatment 4} \\
\hline & & & & & \\
\hline Corn meal & $\%$ & 52.514 & 52.514 & 52.226 & 52.226 \\
\hline Soybean meal $46 \%$ & $\%$ & 32.297 & 32.297 & 32.297 & 32.297 \\
\hline Crude palm oil @ mixer & $\%$ & 2.000 & 2.000 & 2.000 & 2.000 \\
\hline${ }^{2}$ Crude palm oil @ post pelleting & $\%$ & 3.293 & 3.293 & 3.381 & 3.381 \\
\hline Rice bran & $\%$ & 5.000 & 5.000 & 5.000 & 5.000 \\
\hline Corn gluten meal $60 \%$ & $\%$ & 0.613 & 0.613 & 0.613 & 0.613 \\
\hline Di-calcium phosphate $18 \%$ & $\%$ & 1.639 & 1.639 & 1.639 & 1.639 \\
\hline Limestone & $\%$ & 0.889 & 0.889 & 0.889 & 0.889 \\
\hline Salt & $\%$ & 0.310 & 0.310 & 0.310 & 0.310 \\
\hline DL-methionine 99\% & $\%$ & 0.246 & 0.246 & 0.246 & 0.246 \\
\hline${ }^{3}$ Premix & $\%$ & 0.800 & 0.800 & 0.800 & 0.800 \\
\hline Sodium bicarbonate & $\%$ & 0.240 & 0.240 & 0.240 & 0.240 \\
\hline L-Lysine $78 \%$ & $\%$ & 0.082 & 0.082 & 0.082 & 0.082 \\
\hline Choline chloride $75 \%$ & $\%$ & 0.050 & 0.050 & 0.050 & 0.050 \\
\hline L-Threonine $98.5 \%$ & $\%$ & 0.026 & 0.026 & 0.026 & 0.026 \\
\hline${ }^{4}$ Synthetic emulsifier & $\%$ & - & - & 0.050 & - \\
\hline${ }^{5}$ Natural biosurfactant & $\%$ & - & - & - & 0.050 \\
\hline Water & $\%$ & - & 1.000 & 1.000 & 1.000 \\
\hline Wheat pollard & $\%$ & 0.003 & 0.003 & 0.153 & 0.153 \\
\hline \multicolumn{6}{|l|}{ Analysed composition } \\
\hline${ }^{6} \mathrm{GE}$ & $\mathrm{kcal} / \mathrm{kg}$ & 4,238 & 4,230 & 4,220 & 4,229 \\
\hline Dry matter & $\%$ & 89.0 & 88.4 & 88.4 & 88.2 \\
\hline Crude protein & $\%$ & 20.6 & 20.8 & 20.5 & 20.7 \\
\hline Calcium & $\%$ & 0.84 & 0.85 & 0.85 & 0.86 \\
\hline Total phosphorus & $\%$ & 0.76 & 0.74 & 0.75 & 0.75 \\
\hline Lysine & $\%$ & 1.16 & 1.15 & 1.16 & 1.16 \\
\hline Methionine & $\%$ & 0.50 & 0.49 & 0.49 & 0.50 \\
\hline
\end{tabular}

${ }^{1}$ Crude palm oil added during mixing process

${ }^{2}$ Crude palm oil added after pelleting process

${ }^{3}$ Supplied per kg of diet: Fe 40 mg; Zn 100 mg; Mn 120 mg; Cu 20 mg; Se 0.3 mg; vitamin A 10.5 kIU; vitamin D 3.8 kIU; vitamin E 50 mg; vitamin K 2.45 mg; vitamin B 2.68 mg; vitamin $B_{2} 5.88$ mg; vitamin $B_{6} 4.8$ mg; vitamin $B_{12} 0.025$ mg; niacin 58.9 mg; folic acid 1.16 mg; pantothenic acid 12.9 mg; biotin 0.23 mg; ethoxyquin 100 mg; growth promoter $125 \mathrm{mg}$; anticoccidial $550 \mathrm{mg}$; mold inhibitor $500 \mathrm{mg}$.

${ }^{4}$ Each $1 \mathrm{~kg}$ contains $100 \%$ glyceryl polyethylene glycol ricinoleate(Bredol $($, Akzo Nobel, Sweden)

${ }^{5}$ Each $1 \mathrm{~kg}$ contains $250 \mathrm{~g}$ lysophosphatidylcholine (Lysoforte ${ }^{\top M}$, Kemin Industries)

${ }^{6}$ Gross energy 
pellets through Munch RMP 600 pellet mill with the capacity of 18 tonne per hour, $3.5 \mathrm{~mm}$ dies aperture and $55 \mathrm{~mm}$ dies thickness. The pelletized feeds were cooled immediately through Geelen $24 \times 38$ countered flow cooler for 15 minutes of retention time. The mean ambient temperatures in the mill were $30^{\circ} \mathrm{C}$ and $32^{\circ} \mathrm{C}$ during manufacturing of starter and grower feed, respectively. All diets were produced within a day for each feed phase, to eliminate the variable factors that might exist from ingredient variation, machinery configuration setting, condition variation and other production variables associated with feed manufacture. The grower diets were prepared two weeks after the preparation of starter diets.

\section{Measurements and analytical methods}

Mixture of oil, water and emulsifier in Treatment 3 were pre-blended in an emulsitron blender. The sample of this homogeneous colloidal mixture was collected. The effect of emulsion stability was monitored on the separation by visual through emulsion stability test (WHO/M/13.R4, 1999). The impact of feed processing was measured based on the pellet mill energy throughput $(\mathrm{kWh} / \mathrm{T})$ and relative electricity consumption of pellet mill motor.

Electricity consumption, $\mathrm{kW} /(\mathrm{T} / \mathrm{h})=(\mathrm{Amp} \times \mathrm{Vol} \times$ $\sqrt{3} \times$ power factor $) /(\mathrm{T} / \mathrm{h} \times 1000)$

Where $T / h=$ pelleting production rate tonne $\mathrm{p} /$ hour

Amp $=$ average pellet mill motor ampere

Vol $=$ feed mill voltage

Power factor 0.93

Hot mash feed samples were collected from conditioner chamber, while hot pellet feed samples were collected at pellet mill, immediately after pellets were purged out from the pellet mill die holes. Temperature was measured by digital thermometer for both hot mash and hot pellet feed samples. The temperature difference between hot mash and hot pellet feed indicated the temperature created by the friction of pellet mill die hole. Composite feed samples from each treatment were collected from the mixer and cooler in seal plastics. All collected samples were analyzed for moisture content (AOAC, 2005). The same sets of samples were tested for water activity and starch gelatinization. Water activity was determined by obtaining the reading directly from AquaLab Water Activity Meter (Decagon, Series 3TE, US). Gelatinization of starch was determined from the degree of starch that underwent hydrolization by amyloglucosidase enzymatic reaction with specific condition as defined in the Luff-Schoorl method (ISI, 2002). The complete feed was collected from the cooler and was extracted for a known quantity of oil/fat before proceeding for acid value (AOCS, 1999) and peroxide value (AOCS, 1999) evaluation. The chemical stability test on acid value and peroxide value were tested at an interval of 2 days for a period of 14 days. Biostability test on mold count (AOAC, 2005) expressed as cfu/g sample was tested on complete feed on the date of production and the subsequent 7 and 14 days. Physical properties on bulk density and pellet durability index were measured on complete feed which was collected at packing outlet. The bulk density was measured by obtaining the weight of material per liter (ASAE, 1998). Durability of pellet was determined by tumbling $500 \mathrm{~g}$ of sieved sample for $10 \mathrm{~min}$ at $50 \mathrm{rpm}$, in a tumbling box device as described in ASAE S269.4 (1998). The percentage of feed powdery was determined by screening the $50 \mathrm{~kg}$ complete feed through a wire sieve with opening size of $1 \mathrm{~mm}$ and $2 \mathrm{~mm}$ for starter crumble feed and grower pellet feed, respectively. All samples were analyzed in triplicate for each parameter.

\section{Statistical Analysis}

All data from the experiments were calculated using General Linear Model Procedure (GLM) of the Statistical Analysis System (SAS Institute, 2000). Significant differences were analyzed statistically using Least Significant Different (LSD). Treatment means were compared by Duncan's Multiple Range Test using SAS program. Statement of statistical significance was based on probability $p<0.05$, and high significance at $p<0.0001$.

\section{RESULTS}

\section{Energy consumption}

Energy consumption in feed production for starter and grower feeds was represented in Table 3. Diet formulated with water and emulsifier affected the energy usage. Treatment 1 with no addition of water and emulsifier showed the highest $(p<0.05)$ energy consumption with higher energy cost in pelleting process for starter diet. Similar finding was observed in grower feed production. However, inclusion of emulsifier in Treatment 3 and 4, somehow showed no statistical difference. And Treatment 3 with glyceryl polyethylene glycol ricinoleate showed the lowest power consumption and electricity cost compared with all other treatments.

\section{Meal temperature}

The effect of emulsifier on meal process temperature was represented in Table 4, for starter and grower 
Table 3 - Influence of emulsifier on energy consumption in starter and grower feed production

\begin{tabular}{|c|c|c|c|c|c|}
\hline \multirow{2}{*}{ Power consumption } & \multicolumn{4}{|c|}{ Mean \pm SEM } & \multirow{2}{*}{$\mathrm{p}$-value } \\
\hline & Treatment 1 & Treatment 2 & Treatment 3 & Treatment 4 & \\
\hline \multicolumn{6}{|l|}{ Starter } \\
\hline${ }^{1} \mathrm{PR}, \mathrm{T} / \mathrm{h}$ & $15.00 \pm 0.00$ & $15.03 \pm 0.03$ & $15.07 \pm 0.03$ & $15.07 \pm 0.03$ & 0.1889 \\
\hline${ }^{2}$ Motor A, amp & $164.3 \pm 2.33$ & $161.0 \pm 0.58$ & $157.7 \pm 1.33$ & $159.3 \pm 2.33$ & 0.1606 \\
\hline${ }^{3}$ Motor B, amp & $154.7 \pm 8.76$ & $143.3 \pm 0.88$ & $142.3 \pm 1.20$ & $142.0 \pm 2.52$ & 0.2164 \\
\hline${ }^{4}$ Power $A, k W(T / h)$ & $6.70 \pm 0.01^{a}$ & $6.56 \pm 0.02^{\mathrm{ab}}$ & $6.39 \pm 0.04^{c}$ & $6.42 \pm 0.07^{b c}$ & 0.0124 \\
\hline${ }^{5}$ Power B, kW(T/h) & $6.22 \pm 0.05^{a}$ & $5.84 \pm 0.03^{b}$ & $5.77 \pm 0.04^{b}$ & $5.75 \pm 0.11^{b}$ & 0.0066 \\
\hline${ }^{6} \mathrm{Ttl}$ power, kW(T/h) & $12.92 \pm 0.05^{a}$ & $12.40 \pm 0.05^{b}$ & $12.17 \pm 0.08^{b}$ & $12.21 \pm 0.21^{b}$ & 0.0179 \\
\hline${ }^{7}$ Electricity cost, RM & $3.93 \pm 0.02^{\mathrm{a}}$ & $3.77 \pm 0.02^{\mathrm{b}}$ & $3.70 \pm 0.03^{b}$ & $3.71 \pm 0.07^{b}$ & 0.0169 \\
\hline \multicolumn{6}{|l|}{ Grower } \\
\hline${ }^{1} \mathrm{PR}, \mathrm{T} / \mathrm{h}$ & $18.00 \pm 0.00$ & $18.00 \pm 0.00$ & $18.00 \pm 0.00$ & $18.03 \pm 0.03$ & 0.4547 \\
\hline${ }^{2}$ Motor A, amp & $175.0 \pm 0.00^{a}$ & $168.3 \pm 1.20^{b}$ & $165.3 \pm 0.67^{c}$ & $167.3 \pm 0.67^{b c}$ & 0.0005 \\
\hline${ }^{3}$ Motor B, amp & $146.0 \pm 7.21$ & $133.3 \pm 1.76$ & $135.6 \pm 2.73$ & $135.0 \pm 1.53$ & 0.1673 \\
\hline${ }^{4}$ Power A, kW(T/h) & $5.94 \pm 0.01^{a}$ & $5.71 \pm 0.04^{b}$ & $5.61 \pm 0.02^{c}$ & $5.66 \pm 0.01^{b c}$ & 0.0005 \\
\hline${ }^{5}$ Power B, kW(T/h) & $4.83 \pm 0.02^{a}$ & $4.53 \pm 0.06^{b}$ & $4.59 \pm 0.09^{b}$ & $4.56 \pm 0.04^{b}$ & 0.0353 \\
\hline${ }^{6} \mathrm{Ttl}$ power, kW(T/h) & $10.78 \pm 0.01^{a}$ & $10.24 \pm 0.03^{b}$ & $10.20 \pm 0.11^{b}$ & $10.23 \pm 0.04^{b}$ & 0.0009 \\
\hline${ }^{7}$ Electricity cost, RM & $3.28 \pm 0.01^{\mathrm{a}}$ & $3.11 \pm 0.01^{b}$ & $3.10 \pm 0.03^{b}$ & $3.11 \pm 0.01^{b}$ & 0.0006 \\
\hline
\end{tabular}

Treatment 1: Basal diet with 2\% oil at mixer

Treatment 2: Basal diet with $2 \%$ oil at mixer $+1 \%$ water

Treatment 3: Basal diet with $2 \%$ oil at mixer $+1 \%$ water + synthetic emulsifier

Treatment 4: Basal diet with $2 \%$ oil at mixer $+1 \%$ water + natural biosurfactant

a-cMeans within a row with different superscripts differ significantly $(p<0.05)$

SEM: Standard error of mean

'Production rate measured in total tonnage per hour

${ }^{2}$ Pellet mill motor ampere for unit no. A

${ }^{3}$ Pellet mill motor ampere for unit no. B

${ }^{4}$ Electricity consumption calculated in kilowatt ton per hour for pellet mill motor no. A

${ }^{5}$ Electricity consumption calculated in kilowatt ton per hour for pellet mill motor no. B

${ }^{6}$ Total electricity consumption $=$ summation of 4 and 5

${ }^{7}$ Electricity cost $=$ Total electricity consumption $\mathrm{kW}(\mathrm{T} / \mathrm{h})$ times electricity unit cost RM0.304

Currency exchange rate: 1 USD = RM3.70 (as of the time of manuscript preparation)

Table 4 - Effect of emulsifier on meal temperature in the process of starter and grower feed

\begin{tabular}{|c|c|c|c|c|c|}
\hline \multirow{2}{*}{ Temperature, ${ }^{\circ} \mathrm{C}$} & \multicolumn{4}{|c|}{ Mean \pm SEM } & \multirow{2}{*}{$p$-value } \\
\hline & Treatment 1 & Treatment 2 & Treatment 3 & Treatment 4 & \\
\hline \multicolumn{6}{|l|}{ Starter } \\
\hline${ }^{1}$ Hot mash feed & $79.70 \pm 0.40$ & $80.73 \pm 0.41$ & $81.27 \pm 0.22$ & $80.40 \pm 0.64$ & 0.1829 \\
\hline${ }^{2}$ Hot pellet feed & $85.50 \pm 0.06$ & $85.13 \pm 0.18$ & $85.50 \pm 0.15$ & $85.07 \pm 0.32$ & 0.0955 \\
\hline Friction temperature & $6.13 \pm 0.12^{a}$ & $4.40 \pm 0.35^{b}$ & $4.30 \pm 0.32^{b}$ & $4.67 \pm 0.37^{b}$ & 0.0205 \\
\hline \multicolumn{6}{|l|}{ Grower } \\
\hline${ }^{1}$ Hot mash feed & $81.17 \pm 0.27$ & $82.00 \pm 0.42$ & $82.77 \pm 0.52$ & $82.10 \pm 0.06$ & 0.0887 \\
\hline${ }^{2}$ Hot pellet feed & $87.17 \pm 0.52$ & $86.80 \pm 0.50$ & $87.03 \pm 0.67$ & $86.87 \pm 0.13$ & 0.9561 \\
\hline Friction temperature & $6.00 \pm 0.26^{a}$ & $4.80 \pm 0.20^{b}$ & $4.43 \pm 0.33^{b}$ & $4.77 \pm 0.09^{b}$ & 0.0273 \\
\hline
\end{tabular}

Treatment 1: Basal diet with $2 \%$ oil at mixer

Treatment 2: Basal diet with $2 \%$ oil at mixer $+1 \%$ water

Treatment 3: Basal diet with $2 \%$ oil at mixer $+1 \%$ water + synthetic emulsifier

Treatment 4: Basal diet with $2 \%$ oil at mixer $+1 \%$ water + natural biosurfactant

${ }^{a-b}$ Means within a row with different superscripts differ significantly $(p<0.05)$

SEM: Standard error of mean

'Sample collected at conditioner chamber

${ }^{2}$ Sample collected immediately after pellet mill die holes

feeds. Treatment 1, with no addition of water and emulsifier, showed the lowest meal temperature of hot mash feed and the highest temperature of hot pellet feed, resulting in the highest $(p<0.05)$ meal friction temperature. Similar findings were observed in grower diet. However, no significant differences $(p>0.05)$ in meal temperature were observed among Treatments 2, 3 and 4. 
Table $\mathbf{5}$ - Starch gelatinization in processed meal of starter and grower feed

\begin{tabular}{|c|c|c|c|c|c|}
\hline \multirow{2}{*}{ Starch gelatinization, \% } & \multicolumn{4}{|c|}{ Mean \pm SEM } & \multirow{2}{*}{$p$-value } \\
\hline & Treatment 1 & Treatment 2 & Treatment 3 & Treatment 4 & \\
\hline \multicolumn{6}{|l|}{ Starter } \\
\hline 'Gelatinization_M & $23.73 \pm 2.00$ & $23.47 \pm 1.77$ & $24.90 \pm 1.70$ & $25.67 \pm 1.88$ & 0.8700 \\
\hline${ }^{2}$ Gelatinization_C & $30.50 \pm 0.06$ & $34.77 \pm 0.27^{b}$ & $45.57 \pm 0.20^{a}$ & $45.10 \pm 0.12^{\mathrm{a}}$ & $<.0001$ \\
\hline${ }^{3}$ Gelatinization_D & $36.30 \pm 0.06^{c}$ & $36.50 \pm 0.29 c$ & $48.20 \pm 0.12^{\mathrm{a}}$ & $45.20 \pm 1.12^{b}$ & $<.0001$ \\
\hline${ }^{4}$ Gelatinization_P & $36.87 \pm 0.20^{c}$ & $39.63 \pm 0.83^{b}$ & $48.77 \pm 0.15^{\mathrm{a}}$ & $47.77 \pm 0.15^{\mathrm{a}}$ & $<.0001$ \\
\hline \multicolumn{6}{|l|}{ Grower } \\
\hline 'Gelatinization_M & $21.63 \pm 0.48$ & $21.97 \pm 0.84$ & $22.60 \pm 0.52$ & $22.13 \pm 0.80$ & 0.8465 \\
\hline${ }^{2}$ Gelatinization_C & $28.87 \pm 0.09 c$ & $29.90 \pm 0.06^{b}$ & $34.10 \pm 0.12^{\mathrm{a}}$ & $33.90 \pm 0.06^{a}$ & $<.0001$ \\
\hline${ }^{3}$ Gelatinization_D & $34.60 \pm 0.06^{d}$ & $36.37 \pm 0.26^{c}$ & $44.70 \pm 0.12^{\mathrm{a}}$ & $40.17 \pm 0.15^{b}$ & $<.0001$ \\
\hline${ }^{4}$ Gelatinization_P & $34.70 \pm 0.12^{d}$ & $37.20 \pm 0.17 c$ & $47.87 \pm 0.09^{a}$ & $45.10 \pm 0.06^{b}$ & $<.0001$ \\
\hline
\end{tabular}

Treatment 1: Basal diet with $2 \%$ oil at mixer

Treatment 2: Basal diet with $2 \%$ oil at mixer $+1 \%$ water

Treatment 3: Basal diet with $2 \%$ oil at mixer $+1 \%$ water + synthetic emulsifier

Treatment 4: Basal diet with $2 \%$ oil at mixer $+1 \%$ water + natural biosurfactant

a-d Means within a row with different superscripts differ significantly $(p<0.05)$

SEM: Standard error of mean

'Sample collected at mixer

2Sample collected at conditioner chamber

${ }^{3}$ Sample collected immediately after pellet mill die holes

${ }^{4}$ Sample collected after cooler

\section{Gelatinization of starch}

Table 5 shows the effect of emulsifier on starch gelatinization for starter and grower feeds. An increase $(p<0.0001)$ in starch gelatinization was observed in all treatment diets after the conditioning process. The highest gelatinization of starch were obtained in Treatments 3 and 4 (with water and emulsifier inclusion in the diet), followed by Treatment 2 (with water addition and no emulsifier in the diet), and the lowest in Treatment 1 (with no water and no emulsifier in the diet). A similar finding was observed in grower feed. Treatment 3 with glyceryl polyethylene glycol ricinoleate showed the highest $(p<0.0001)$ starch gelatinization after cooling process in grower feed compared to all other treatments.

\section{Pellet quality}

As indicated in Table 6, Treatment 1 showed the highest $(p<0.05)$ feed density compared to other treatment diets. However, no significant difference result

Table 6 - Pellet quality on starter and grower feed supplemented with emulsifier

\begin{tabular}{|c|c|c|c|c|c|}
\hline \multirow{2}{*}{ Pellet quality } & \multicolumn{4}{|c|}{ Mean \pm SEM } & \multirow{2}{*}{$p$-value } \\
\hline & Treatment 1 & Treatment 2 & Treatment 3 & Treatment 4 & \\
\hline \multicolumn{6}{|l|}{ Starter } \\
\hline Crumble $>1 \mathrm{~mm}, \%$ & $84.17 \pm 0.74^{c}$ & $85.17 \pm 1.73^{b c}$ & $90.97 \pm 1.30^{a}$ & $89.40 \pm 0.84^{a b}$ & 0.0285 \\
\hline Fine $<1 \mathrm{~mm}, \%$ & $15.83 \pm 0.74^{a}$ & $14.83 \pm 1.73^{\mathrm{ab}}$ & $9.03 \pm 1.30^{c}$ & $10.60 \pm 0.84^{b c}$ & 0.0288 \\
\hline 'Density_C, g/l & $610.7 \pm 2.19^{a}$ & $585.7 \pm 6.36^{b}$ & $574.7 \pm 4.70^{b}$ & $585.7 \pm 5.78^{b}$ & 0.0028 \\
\hline ²Density_P, g/l & $668.3 \pm 4.48^{a}$ & $654.0 \pm 4.04^{b}$ & $645.3 \pm 1.45^{b}$ & $646.3 \pm 1.76^{b}$ & 0.0082 \\
\hline${ }^{3} \mathrm{PDI}$ & $93.30 \pm 0.06$ & $94.03 \pm 0.38$ & $94.60 \pm 0.58$ & $93.30 \pm 0.71$ & 0.2353 \\
\hline \multicolumn{6}{|l|}{ Grower } \\
\hline Pellet > 2mm, \% & $95.60 \pm 0.21^{c}$ & $96.87 \pm 0.26^{b}$ & $97.93 \pm 0.09^{a}$ & $97.07 \pm 0.38^{a b}$ & 0.0044 \\
\hline Fine $<2 \mathrm{~mm}, \%$ & $4.40 \pm 0.21^{\mathrm{a}}$ & $3.13 \pm 0.26^{b}$ & $2.07 \pm 0.09 c$ & $2.93 \pm 0.38^{b c}$ & 0.0044 \\
\hline${ }^{2}$ Density_P, g/l & $654.0 \pm 3.51^{\mathrm{a}}$ & $637.7 \pm 3.33^{b}$ & $641.3 \pm 4.71^{b}$ & $637.0 \pm 1.53^{b}$ & 0.0436 \\
\hline${ }^{3} \mathrm{PDI}$ & $90.70 \pm 0.17^{b}$ & $92.80 \pm 0.21^{a}$ & $93.07 \pm 0.54^{a}$ & $92.70 \pm 0.29^{a}$ & 0.0055 \\
\hline
\end{tabular}

Treatment 1: Basal diet with $2 \%$ oil at mixer

Treatment 2: Basal diet with $2 \%$ oil at mixer $+1 \%$ water

Treatment 3: Basal diet with $2 \%$ oil at mixer $+1 \%$ water + synthetic emulsifier

Treatment 4: Basal diet with $2 \%$ oil at mixer $+1 \%$ water + natural biosurfactant

accMeans within a row with different superscripts differ significantly $(p<0.05)$

SEM: Standard error of mean

'Feed bulk density in crumble form, expressed in gram per litre

${ }^{2}$ Feed bulk density in pellet form, expressed in gram per litre

${ }^{3}$ Pellet Durability Index 
was found on diets supplemented with water and emulsifiers. Treatment 1 with the highest bulk density showed the lowest $(p<0.05)$ pellet durability index in grower feed. There was no significant difference ( $p>0.05$ ) between emulsifier glyceryl polyethylene glycol ricinoleate in Treatment 3 and lysophosphatidylcholine in Treatment 4 on pellet quality.

\section{Moisture and water activity}

Water activity (Aw) detected in all stages of experimental diets ranged from 0.61 to 0.69 (Table 7). Treatment 1 showed the lowest Aw in mash feed after mixing process $(p<0.0001)$ and complete feed after cooling process $(p<0.05)$. The effect of emulsifier on water activity was observed in Treatments 3 and 4 during mixing process for grower phase $(p<0.05)$. Treatment 1 possessed the lowest $(p<0.05)$ moisture content throughout the whole process. Water addition in the experimental diet increased the moisture content in mash feed. Emulsifier supplemented diet retained it's high moisture content until the final cooler stage in starter diet $(p<0.05)$ but not in grower diet. There was no significant difference ( $p>0.05)$ between synthetic emulsifier glyceryl polyethylene glycol ricinoleate in Treatments 3 and biosurfactant lysophosphatidyl- choline in Treatment 4 on feed moisture and water activity.

\section{Acid value}

As summarized in Table 8, all the treatment diets showed an increased level of acid value after being kept for 14 days. However, the increased rate showed no significant difference ( $p>0.05)$ among the experimental diets. Similar findings were observed in grower feed.

\section{Peroxide value}

Table 9 shows an increased level of peroxide value in all treatment diets after keeping for 14 days. No significant difference ( $p>0.05$ ) was found among the experimental diets on the increased rate of peroxide value.

\section{Biostability}

All the treatment diets were not statistically significant $(p>0.05)$ for the mold count. The situation remained unchanged after 7 and 14 days. Similar findings were found in grower feed as represented in Table 10.

Table 7 - Effect of emulsifier on meal moisture and water activity in starter and grower feed

\begin{tabular}{|c|c|c|c|c|c|}
\hline \multirow{2}{*}{$\begin{array}{l}\text { Water activity / Moisture, } \\
\%\end{array}$} & \multicolumn{4}{|c|}{ Mean \pm SEM } & \multirow{2}{*}{ p-value } \\
\hline & Treatment 1 & Treatment 2 & Treatment 3 & Treatment 4 & \\
\hline \multicolumn{6}{|l|}{ Starter } \\
\hline${ }^{1} A w \_D$ & $0.64 \pm 0.00^{b}$ & $0.67 \pm 0.00^{a}$ & $0.68 \pm 0.00^{a}$ & $0.67 \pm 0.00^{a}$ & $<.0001$ \\
\hline${ }^{2} A w \_P$ & $0.64 \pm 0.00^{b}$ & $0.67 \pm 0.00^{a}$ & $0.68 \pm 0.00^{a}$ & $0.67 \pm 0.01^{a}$ & 0.0229 \\
\hline${ }^{3}$ Moisture_M & $11.60 \pm 0.01^{b}$ & $12.17 \pm 0.10^{a}$ & $12.27 \pm 0.06^{a}$ & $12.14 \pm 0.08^{a}$ & 0.0026 \\
\hline${ }^{4}$ Moisture_C & $13.87 \pm 0.06^{c}$ & $14.56 \pm 0.07^{b}$ & $15.04 \pm 0.10^{a}$ & $14.82 \pm 0.17^{a b}$ & 0.0011 \\
\hline${ }^{5}$ Moisture_D & $12.84 \pm 0.01^{b}$ & $14.42 \pm 0.05^{a}$ & $14.23 \pm 0.09^{a}$ & $13.90 \pm 0.27^{a}$ & 0.0012 \\
\hline${ }^{6}$ Moisture_P & $11.05 \pm 0.04^{c}$ & $11.73 \pm 0.06^{b}$ & $12.19 \pm 0.15^{a}$ & $12.01 \pm 0.16^{a b}$ & 0.0003 \\
\hline \multicolumn{6}{|l|}{ Grower } \\
\hline${ }^{1} A w \_D$ & $0.64 \pm 0.00^{c}$ & $0.69 \pm 0.00^{a}$ & $0.68 \pm 0.00^{b}$ & $0.68 \pm 0.00^{b}$ & $<.0001$ \\
\hline${ }^{2} A w_{-} P$ & $0.61 \pm 0.00^{b}$ & $0.65 \pm 0.00^{a}$ & $0.64 \pm 0.00^{a}$ & $0.64 \pm 0.00^{\mathrm{a}}$ & 0.0013 \\
\hline${ }^{3}$ Moisture_M & $11.65 \pm 0.03^{b}$ & $12.65 \pm 0.04^{a}$ & $12.66 \pm 0.17^{a}$ & $12.52 \pm 0.23^{a}$ & 0.0134 \\
\hline${ }^{4}$ Moisture_C & $14.19 \pm 0.04^{c}$ & $15.45 \pm 0.11^{a b}$ & $15.92 \pm 0.15^{a}$ & $15.26 \pm 0.21^{b}$ & 0.0008 \\
\hline${ }^{5}$ Moisture_D & $13.41 \pm 0.02^{c}$ & $14.79 \pm 0.19^{a b}$ & $15.00 \pm 0.11^{a}$ & $14.40 \pm 0.17^{b}$ & 0.0017 \\
\hline${ }^{6}$ Moisture_P & $11.26 \pm 0.04^{b}$ & $11.95 \pm 0.06^{a}$ & $12.14 \pm 0.18^{a}$ & $12.05 \pm 0.07^{a}$ & 0.0020 \\
\hline
\end{tabular}

Treatment 1: Basal diet with $2 \%$ oil at mixer

Treatment 2: Basal diet with $2 \%$ oil at mixer $+1 \%$ water

Treatment 3: Basal diet with $2 \%$ oil at mixer $+1 \%$ water + synthetic emulsifier

Treatment 4: Basal diet with $2 \%$ oil at mixer $+1 \%$ water + natural biosurfactant

a-cMeans within a row with different superscripts differ significantly $(p<0.05)$

SEM: Standard error of mean

'Water activity for sample collected at mixer

${ }^{2}$ Water activity for sample collected after cooler

${ }^{3}$ Moisture content for sample collected at mixer

${ }^{4}$ Moisture contentfor sample collected at conditioner chamber

${ }^{5}$ Moisture content for sample collected immediately after pellet mill die holes

${ }^{6}$ Moisture content for sample collected after cooler 
Table $\mathbf{8}$ - Increased rate of acid value in starter and grower feed throughout 14 days of storage period

\begin{tabular}{|c|c|c|c|c|c|}
\hline \multirow{2}{*}{ Days of storage } & \multicolumn{4}{|c|}{ Increased rate of $\mathrm{AV}, \mathrm{mg} \mathrm{KOH} / \mathrm{g}$ (mean $\pm \mathrm{SEM})$} & \multirow{2}{*}{$p$-value } \\
\hline & Treatment 1 & Treatment 2 & Treatment 3 & Treatment 4 & \\
\hline \multicolumn{6}{|l|}{ Starter } \\
\hline 4 & $2.30 \pm 0.13$ & $1.97 \pm 0.17$ & $2.13 \pm 0.11$ & $2.01 \pm 0.11$ & 0.2742 \\
\hline 6 & $3.02 \pm 0.20$ & $2.28 \pm 0.07$ & $2.83 \pm 0.42$ & $2.42 \pm 0.14$ & 0.0736 \\
\hline 8 & $4.19 \pm 0.38$ & $4.13 \pm 0.49$ & $4.12 \pm 0.51$ & $3.28 \pm 0.19$ & 0.4930 \\
\hline 10 & $5.80 \pm 0.28$ & $6.05 \pm 0.34$ & $6.94 \pm 0.20$ & $5.93 \pm 0.46$ & 0.1144 \\
\hline 12 & $9.56 \pm 0.38$ & $8.34 \pm 0.24$ & $8.77 \pm 0.16$ & $9.42 \pm 0.20$ & 0.0811 \\
\hline 14 & $10.50 \pm 0.27$ & $9.84 \pm 0.42$ & $10.46 \pm 0.31$ & $10.70 \pm 0.38$ & 0.4494 \\
\hline \multicolumn{6}{|l|}{ Grower } \\
\hline 4 & $1.96 \pm 0.26$ & $1.68 \pm 0.61$ & $0.66 \pm 0.08$ & $2.14 \pm 0.61$ & 0.2557 \\
\hline 6 & $3.43 \pm 0.29$ & $2.92 \pm 0.35$ & $3.16 \pm 0.33$ & $4.33 \pm 0.26$ & 0.0606 \\
\hline 8 & $5.00 \pm 0.84$ & $4.69 \pm 0.34$ & $4.43 \pm 0.39$ & $6.03 \pm 0.25$ & 0.2629 \\
\hline 10 & $6.68 \pm 0.17$ & $5.92 \pm 0.25$ & $5.96 \pm 0.31$ & $6.85 \pm 0.31$ & 0.1391 \\
\hline 12 & $7.16 \pm 0.41$ & $7.08 \pm 0.34$ & $7.13 \pm 0.52$ & $8.99 \pm 0.57$ & 0.1178 \\
\hline 14 & $8.48 \pm 0.22$ & $8.76 \pm 0.86$ & $8.63 \pm 0.64$ & $10.42 \pm 0.13$ & 0.2107 \\
\hline
\end{tabular}

Treatment 1: Basal diet with $2 \%$ oil at mixer

Treatment 2: Basal diet with $2 \%$ oil at mixer $+1 \%$ water

Treatment 3: Basal diet with $2 \%$ oil at mixer $+1 \%$ water + synthetic emulsifier

Treatment 4: Basal diet with $2 \%$ oil at mixer $+1 \%$ water + natural biosurfactant

Means within a row with no superscripts has no significant difference $(p<0.05)$

SEM: Standard error of mean

Table 9 - Changes of peroxide value in starter and grower feed throughout 14 days of storage period

\begin{tabular}{|c|c|c|c|c|c|}
\hline \multirow{2}{*}{ Days of storage } & \multicolumn{4}{|c|}{ Increased rate of $\mathrm{PV}, \mathrm{mEq} / \mathrm{kg}$ (mean $\pm \mathrm{SEM})$} & \multirow{2}{*}{$p$-value } \\
\hline & Treatment 1 & Treatment 2 & Treatment 3 & Treatment 4 & \\
\hline \multicolumn{6}{|l|}{ Starter } \\
\hline 4 & $0.62 \pm 0.10$ & $0.55 \pm 0.12$ & $0.29 \pm 0.03$ & $0.44 \pm 0.05$ & 0.1647 \\
\hline 6 & $1.76 \pm 0.22$ & $1.22 \pm 0.21$ & $1.14 \pm 0.30$ & $0.90 \pm 0.26$ & 0.1897 \\
\hline 8 & $2.41 \pm 0.01$ & $1.99 \pm 0.22$ & $2.31 \pm 0.15$ & $1.82 \pm 0.17$ & 0.1466 \\
\hline 10 & $2.70 \pm 0.09$ & $2.25 \pm 0.13$ & $2.56 \pm 0.12$ & $2.14 \pm 0.13$ & 0.0841 \\
\hline 12 & $3.08 \pm 0.12$ & $3.03 \pm 0.08$ & $2.94 \pm 0.14$ & $2.92 \pm 0.20$ & 0.8954 \\
\hline 14 & $3.35 \pm 0.07$ & $3.34 \pm 0.13$ & $3.04 \pm 0.13$ & $3.00 \pm 0.18$ & 0.2285 \\
\hline \multicolumn{6}{|l|}{ Grower } \\
\hline 4 & $0.53 \pm 0.10$ & $0.85 \pm 0.31$ & $1.01 \pm 0.17$ & $1.02 \pm 0.32$ & 0.5363 \\
\hline 6 & $1.12 \pm 0.08$ & $1.31 \pm 0.10$ & $1.72 \pm 0.10$ & $1.43 \pm 0.32$ & 0.2716 \\
\hline 8 & $2.12 \pm 0.16$ & $1.73 \pm 0.14$ & $2.19 \pm 0.12$ & $2.29 \pm 0.31$ & 0.2481 \\
\hline 10 & $2.54 \pm 0.20$ & $2.31 \pm 0.12$ & $2.51 \pm 0.04$ & $2.70 \pm 0.13$ & 0.2886 \\
\hline 12 & $2.77 \pm 0.14$ & $2.48 \pm 0.16$ & $2.48 \pm 0.16$ & $2.95 \pm 0.10$ & 0.1099 \\
\hline 14 & $3.08 \pm 0.09$ & $2.79 \pm 0.17$ & $2.89 \pm 0.05$ & $3.17 \pm 0.17$ & 0.3386 \\
\hline
\end{tabular}

Treatment 1: Basal diet with 2\% oil at mixer

Treatment 2: Basal diet with $2 \%$ oil at mixer $+1 \%$ water

Treatment 3: Basal diet with $2 \%$ oil at mixer $+1 \%$ water + synthetic emulsifier

Treatment 4: Basal diet with $2 \%$ oil at mixer $+1 \%$ water + natural biosurfactant

Means within a row with no superscripts has no significant difference $(p<0.05)$

SEM: Standard error of mean

\section{DISCUSSION}

\section{Energy consumption}

Diet formulated with water and emulsifier significantly reduced total electricity consumption in feed milling. This finding might be due to lubrication effect (Ryu \& Walker, 1994) on moist meal, the feed granules passing through the die hole of pellet mill with lower motor ampere, resulting in lower pellet mill energy throughput and thus lower electricity cost.

\section{Meal temperature}

Low meal temperature of hot mash feed in Treatment 1 could be probably due to the incomplete steam penetration and heat transferred into the meal particle during the conditioning process (Moritz et al., 
Table 10 - Biostability on mold count in starter and grower feed supplemented with emulsifier

\begin{tabular}{|c|c|c|c|c|c|}
\hline \multirow{2}{*}{ Days of storage } & \multicolumn{4}{|c|}{ Mold count, cfu/g (mean \pm SEM) } & \multirow{2}{*}{$\mathrm{p}$-value } \\
\hline & Treatment 1 & Treatment 2 & Treatment 3 & Treatment 4 & \\
\hline \multicolumn{6}{|l|}{ Starter } \\
\hline 0 & $5.00 \pm 2.89$ & $10.00 \pm 5.77$ & $5.00 \pm 2.89$ & $6.67 \pm 3.33$ & 0.8112 \\
\hline 7 & $11.67 \pm 4.41$ & $0.00 \pm 0.00$ & $6.67 \pm 3.33$ & $11.67 \pm 1.67$ & 0.0951 \\
\hline 14 & $5.00 \pm 2.89$ & $3.33 \pm 3.33$ & $0.00 \pm 0.00$ & $10.00 \pm 5.77$ & 0.2271 \\
\hline \multicolumn{6}{|l|}{ Grower } \\
\hline 0 & $5.00 \pm 2.89$ & $0.00 \pm 0.00$ & $0.00 \pm 0.00$ & $0.00 \pm 0.00$ & 0.1170 \\
\hline 7 & $5.00 \pm 2.89$ & $0.00 \pm 0.00$ & $6.67 \pm 3.33$ & $6.67 \pm 6.67$ & 0.6697 \\
\hline 14 & $8.33 \pm 1.67$ & $0.00 \pm 0.00$ & $3.33 \pm 3.33$ & $0.00 \pm 0.00$ & 0.0884 \\
\hline
\end{tabular}

Treatment 1: Basal diet with 2\% oil at mixer

Treatment 2: Basal diet with $2 \%$ oil at mixer $+1 \%$ water

Treatment 3: Basal diet with $2 \%$ oil at mixer $+1 \%$ water + synthetic emulsifier

Treatment 4: Basal diet with $2 \%$ oil at mixer $+1 \%$ water + natural biosurfactant

Means within a row with no superscripts has no significant difference $(p<0.05)$

SEM: Standard error of mean

2003). Lubrication effect on the meal particle was not achieved, leading to high friction heat and shear force creation when moist meal passes through the pellet mill die holes. However, inclusion of water and emulsifier in Treatments 2, 3 and 4 have served as a transaction phase for heat absorption, whereby the effect of steam penetration was achieved, resulting in higher temperature of hot mash feed compared to Treatment 1. An endothermic reaction of gelatinization process in starch-lipid complex formation (Ali \& Hasnain, 2013) could have taken place in Treatments 2,3 and 4 after the conditioning process. The explanation was supported by the result of the high starch gelatinization (Table 5), and low meal temperature of hot pellet feed (Table 4), which has provided an indication for the endothermic reaction.

\section{Gelatinization of starch}

Improvement of starch gelatinization was observed in diets with water and emulsifier. This could be explained due to the emulsification effect of water and steam, which dispersed into the oil coated meal particle of the diet. The processed steam is capable to form a stable emulsion and reduced surface tension, which allows steam penetrating into the meal granules. As starch particles in the diet is heated in the presence of excessive water, in the form of steam in the conditioner chamber, starch granules start to gelatinize (Thomas \& Poel, 1998), forming a mixture of fragments, swollen granules and colloidal starch (Olkku \& Rha, 1978). In addition, during the gelatinization process, those swollen starch granules were fragile and could easily rupture under shear force, and therefore decreased the viscosity of meal mixture (Ahmadi-Abhari et al., 2013). Addition of emulsifier can stabilize the swollen starch granules from rupture (Azizi \& Rau, 2005). The explanation could be due to the properties of the emulsifier, which is capable to delay the starch swelling effect in the amylose-lipid complex formation. The formation from the linear portion of amylose, and to some extent, the amylopectin chain has formed a helix coil around the lipid fatty acid, forming a stabilized layer of lipid film around the starch granules (Leloup et al., 1992). In this study, synthetic emulsifier glyceryl polyethylene glycol ricinoleate in Treatment 3 showed higher $(p<0.0001)$ effect in starch gelatinization than natural biosurfactant lysophosphatidylcholine in Treatment 4 and other treatments during the pelleting process. The emulsification of fat as well as the thermomechanical friction, resulting from the pelleting process, would further enhance the gelatinization of starch (Stauffer, 1999). The formation of amorphous or crystalline structure in the amylose-lipid complex in gelatinization process, was reported to depends on the interactions between heating temperature, water content in the starch-lipid structure, and the extent of amylose leached out from the starch granule (Le Bail et al., 1999). The effect would be extended to the complete feed after the cooling process. Lysophosphatidylcholine, a natural biosurfactant which targets to disperse oil droplet in the water environment at animal digestive gut, has somehow shown some degree of emulsifying effect in starch gelatinization during feed manufacturing $(p<0.0001)$. The amphoteric characteristic of lysophosphatidylcholine that possesses anionic negative charge on hydroxyl group and cationic positive charge on nitrogen end, was capable to exhibit some dispersion effect on water-oil and oil-water environment (Yamanaka et al., 1997). Regardless of the electrostatic effect, both 
ionic and non-ionic emulsifiers were reported have the same effect in starch-lipid complex-forming properties in gelatinization process (Nuessli et al., 2000).

\section{Pellet quality}

Results of the present experiment showed that diets with water possessed low feed density values. Pellet quality was noted to increase with the decrease of bulk density. In this experiment treatment, diets 2, 3 and 4 with low bulk density, showed high pellet durability index $(P D I)$ in grower feed $(p<0.05)$. This could be due to the confound moisture effect on bulk density, that created more intact pellet and better pellet quality (Moritz et al., 2002). Treatment 1, without water addition, was observed to have the lowest physical quality in the final feed product as compared with other treatments. The improvement in physical quality was further enhanced on diets supplemented with water and emulsifier in Treatments 2, 3 and 4. Higher $(p<0.05)$ intact form of crumble and pellet in starter and grower feeds were observed in emulsifier supplemented diet. This could be explained by greater meal moisture (Table 7 ), together with higher conditioner temperature and decreased frictional heat (Table 4), leading to better gelatinization of starch (Table 5), thus improved in pellet formation. In the presence of excessive water, crystalline starch granules absorb water through hydrogen bonding with their free hydroxyl group and swell. In the process of high temperature, starch molecules absorb energy, dissociate the double helices and form into amorphous. Starch granule losses it's crystalline structure, losses in molecule order and increases in viscosity (Eliasson \& Gudmundsson, 2006). This starch gelatinization process has contributed to the lubrication effect which allowed the pellet to be flashed off more efficiently from the die. The lubricant effect has minimized the friction and thus decreased the frictional heat (Table 4 ) in the pelleting process. After the cooling process, the gelatinized starch molecule was re-associated, recrystallized and re-structured back to the double helical through the formation of non-covalent interactions of amylose molecules (Thomas \& Atwell, 1999). The dispersed matrix of gelatinized starch forms a pastelike gel which functions as a binding agent. The pellet feed was formed by starchy gumming material within the meal particle, hardening the exterior pellet surface while leaving the interior mealy (Froestschner, 2007). The increase in starch gelatinization (Table 5) explained the improvement in pellet quality, increased of PDI, intact feed form and reduced powdery portion. The use of water and exogenous emulsifier resulted in better starch gumming effect, which functions as an adhesive in pellet binding, thus aiding in durable pellet formation (Froetschner, 2007), and enabling us to create more intact pellet and little/minimum fines.

\section{Moisture and water activity}

The moisture content in the feed, determined the yield and confirmed the end point of dry weight. The shelf stability associated with the loss of water content is influenced by the water activity (Aw), the ratio of the vapor pressure $(\mathrm{P})$ in a product and that of pure water at the same temperature (Po). Thus, the relationship between water activity and moisture content is correlated by the equilibrium of relative humidity $(\mathrm{ERH})$ of the surrounding atmosphere (ERH $=$ Aw x 100\%), (Eskin \& Robinson, 2001). Apparently, adding water in the diets increased the moisture content and water activity (Aw) in the processed meal. At a constant temperature and for each humidity value, the relationship between moisture content and water activity is indicated by the corresponding moisture sorption isotherm. The sorption behavior changes accordingly to the material composition and quality changes. Due to the complexity of product composition, theoretical prediction of isotherms cannot be determined by calculation. The complexity of sorption process somehow needs to be measured experimentally for individual material (Bell \& Labuza, 2000). The moisture content and water activity obtained in this experiment, indicated the relationship of moisture sorption isotherm in the poultry feed, under the specific temperature and equilibrium of relative humidity with the surrounding atmosphere of the experimental environment. Treatment 1 possessed the lowest Aw compared with other treatments supplemented with water and emulsifier. A possible explanation is that the addition of water in the experimental diets in Treatments 2, 3 and 4, had increased the amount of free moisture, evident from the outcome on water activity (Table 7). This free water was driven off more efficiently from the pellet feed. Surface tension of free water was expected to be firmly bounded in the feedstuff granules in diets supplemented with emulsifier, which minimized the water migration, and increased the water retention in feed particle.

\section{Acid value}

Acid value is an indicator to identify the deterioration of oil due to hydrolytic rancidity. It measured the amount of potassium hydroxide in milligram that is needed to neutralize the fatty acid of the oil or fat. In the presence of moisture, this hydrolysis oxidation increased the 
level of acid value of the experiment diets throughout 14 days of storage period. The reaction could be catalyzed by lipase enzyme that might be present naturally in the plant oils or animal fats of the feed's ingredients (Rossel, 1994). The rate of this enzymatic peroxidation was gradual, which could be due to the limitation of those natural existence enzymes. In this experiment, the suspension of aqueous droplet in oil medium, associated with the emulsifier molecules from the emulsification process, has reduced the surface tension between water and oil phases (Stauffer, 1999). However, this process somehow showed no significant deterioration rancidity effect on the treated diets.

\section{Peroxide value}

The elevated peroxide value caused by chemical reaction was measured as an indicator of oxidation rancidity (Antolovich et al., 2002). This reaction involved the addition of oxygen from the environment's reaction to the unsaturated fatty acids. Degradation of lipids took place forming the initial hydro-peroxides. Auto-oxidation occurred in the subsequent free-radical mechanism resulting in hydrocarbon and several other compounds of epoxides and alcohol formation. The inclusion of water and emulsifier in this study showed no significant difference in lipid degradation of the experimental diets. Slow increased rate of peroxide formation in the diets after 14 days could be explained due to the inclusion of antioxidant in the poultry diet, which inhibits the reaction between antioxidant and free radicals that slow down the auto-oxidation or natural formation of peroxides from deteriorating (Gutteridge \& Halliwell, 2010). The antioxidants could be partitioning into different phases of emulsion, either in oil phase, water phase or interface between these 2 phases with it's respective efficacy to affect the oxidation rate (Sorensen et al., 2008).

\section{Biostability}

Generally microorganisms require optimum level of water activity and depend on other environment factors for growth. It has been reported that microorganisms require water as solution for cell contents, generally best grown between Aw 0.995 - 0.980 (Gibbs \& Gekas, 1999). Although water and emulsifier were added in this experiment, the water activity in these treated diets was tested ranging from 0.61 to 0.69 , which was far below the microbial growth range. The experimental diets were relative stable from propagation of air borne or water borne microbial and bacterial contamination. The level of mold count remained stable for 14 days regardless of any of the treated diets. Emulsification showed no significant effect for the microbial response. Although some yeasts and molds might grow in the environment with water activity lower than 0.60 , an inclusion of mold inhibitor in the diet does not interfere on the mold growth effect.

\section{CONCLUSIONS}

From this study, it is concluded that adding water and emulsifier to a corn-soy based broiler diet has no deteriorating effect in hydrolytic rancidity, oxidation rancidity and biostability of the pellet feed. Significant differences showed in moisture content, water activity and meal temperature has provided valuable information on the effect of water and emulsifier to the gelatinization of starch, which contributed to the physical properties of the pellet feed. The effect of different types of emulsifier did not improve electricity consumption. It is concluded that the effect of the emulsifier in economic savings was not found in this specific experimental design.

\section{ACKNOWLEDGEMENTS}

This research project was made possible by the support and facilities of Charoen Pokphand Holdings, Malaysia. This project was supported by Long-Term Research Grant Scheme (LRGS) from Ministry of Education of Malaysia.

\section{REFERENCES}

Ahmadi-Abhari S, Woortman AJJ, Hamer RJ, Oudhuis AACM, Loos K. Influence of lysophosphatidylcholine on the gelation of diluted wheat starch suspensions. Carbohydrate Polymers 2013;93:224-231.

Ali TM, Hasnain A. Effect of emulsifiers on complexation and retrogradation characteristics of native and chemically modified white sorghum (sorghum bicolor) starch. Thermochimica Acta 2013;552:46-53.

Antolovich M, Prenzler PD, Patsalides E, McDonald S, Robards K. Methods for testing antioxidant activity. Analyst 2002;127(1):183-198.

AOAC - Association of Official Analytical Chemists. $18^{\text {th }}$ ed. Washington: Official methods of Analysis; 2005.

AOCS - American Oil Chemists' Society. Official methods and recommended practices of the american oil chemists. $3^{\text {rd }}$ ed. Washington; 1999.

ASAE - American Society of Agricultural Engineers. Cubes, pellets, and crumbles: definitions and methods for determining density, durability, and moisture content [S269].St Joseph: ASAE; 1998.

Attawong S, Fahrenholz AC, Brake J. The effect of dietary corn particle size and post-pellet liquid fat application on broiler live performance. Poultry Science 2014;93(1):26. 
Azizi MH, Rau VG. Effect of surfactant in pasting characteristics of various starches. Food Hydrocolloids 2005;19(4):739-743.

Bell LN, Labuza TP. Practical aspects of moisture sorption isotherm measurement and use. $2^{\text {nd }} e d$. St Paul: AACC Eagan Press; 2000.

Brill Feed Formulation ${ }^{\mathrm{TM}}$ System. Feed management systems. Brilliant Alternatives; 2005. v.1, p.36

Buchanan NP, Lilly KGS, Gehring CK, Moritz JS. The effects of altering diet formulation and manufacturing technique on pellet quality. Journal of Applied Poultry Research 2010;19:112-120.

Cavalcanti WB, Behnke KC. Effect of composition of feed model systems. On Pellet Quality. Cereal Chemistry 2005;82(4):462-467.

Cobb 500. Broiler performance and nutrition supplement. Siloam: CobbVantress; 2015

CPM - California Pellet Mill. Animal feed pelleting application. Crawfordsville: The Pelleting Process. p.1-33.

Eliasson AC, Gudmundsson M. Starch: physicochemical and functional aspects. Florida: CRC Press; 2006. p.391-486.

Eskin NAM, Robinson DS. Food shelf life stability. Chemical, biochemical and microbiological changes. Florida: CRC Press; 2001.

Froetschner JR. Micro-ingredient application and equipment: Issues and advances. Animal Feed Manufacturers' Association 2007;16(2):12-19.

Gibbs P, Gekas V. Water activity and microbiological aspect of foods - a knowledge base. 1999. Available from: http://www.nelfood.com.

Gutteridge JMC, Halliwell B. Antioxidants: Molecules, medicines, andmyths. Biochemical and Biophysical Research Communications 2010;393(4):561-564.

Hasenhuettl GL, Hartel RW. Physicochemical aspects of an emulsifier functionality. $2^{\text {nd }}$ ed. Food emulsifiers and their applications. New York: Springer; 2008. p. 173-193.

ISI, 28-1e. Determination of reducing sugar, DE by Luff-Schoorl's method, LT 1/9/1970, Rev LT 22/1;2002.

Le Bail P, Bizot H, Ollivon M, Keller G, Bourgaux C, Bule'on A. Monitoring the crystallization of amylose-lipid complexes during maize starch melting by synchrotron X-ray diffraction. Biopolymers 1999;50:99-110.

Leloup VM, Colonna P, Ring SG, Roberts K, Wells B. Microstructure of amylose gels. Carbohydrate polymers 1992;18(3):189-197.
Moritz JS, Cramer KR, Wilson KJ, Beyer RS. Effect of feed rations with graded levels of added moisture formulated to different energy densities on feed manufacturing, pellet quality, performance and energy metabolism of broilers during the growing period. Journal of Applied Poultry Research 2003;12:371-381.

Moritz JS, Wilson KJ, Cramer KR, Beyer RS, McKinney LJ, Cavalcanti WB, et al. Effect of formulation density, moisture and surfactant on feed manufacturing, pellet quality and broiler performance. Journal of Applied Poultry Research 2002;11:155-163.

Nuessli J, Handschin S, Conde-Petit B, Escher F. Rheology and structure of amylopectin potato starch dispersions without and with emulsifier addition, Starke 2000;52(1):22-27.

Olkku T, Rha C. Gelatinization of starch and wheat flour a review. Food Chemistry 1978;3:293-317

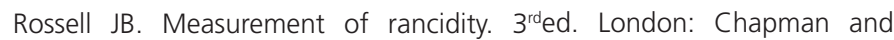
Hall;1994. p.22-53.

Ryu GH, Walker CE. Cell structure of wheat flour extrudates produced with various emulsifiers. Lebensmitte-Wissenchaft und-Technologie 1994:27:432-441

SAS. User guide statistics. Cary: SAS Institute; 2000.

Sorensen ADM, Haahr AM, Becker EM, Skibsted LH, Bergenstahl B, Nilsson $L$, et al. Interactions between iron, phenolic compounds, emulsifiers and $\mathrm{pH}$ in omega-3 enriched oil-in-water emulsions. Journal of Agricultural and Food Chemistry 2008;56(5):1740-1750.

Stauffer CE. Emulsifiers. St Paul: Eagan Press; 1999

Thomas DJ, Atwell WA. Starches. St Paul: Eagen Press; 1999.

Thomas M, van Vliet T, van der Poel AFB. Physical quality of pelleted animal feed 3. Contribution of feedstuff components. Animal Feed Science Technology 1998;70:59-78.

WHO - World Health Organization. Emulsion stability test specification [/M/13.R4]. Genebra;1999.

Yamanaka T, Ogihara N, Ohhori T, Hayashi H, Muramatsu T. Surface chemical properties of homologs and analogs of lysophosphatidylcholine and lysophosphatidylethanolamine in water. Chemistry and Physics of Lipids 1997;90:97-107.

Ziggers D. The better the pellet, the better the performance. 2012. Available from: http://www.allaboutfeed.net/Nutrition/Research/2012/2/Thebetter-the-pellet-the-better-the-performance-AAF012746W/ 